\title{
Effect of silica aerogel on the thermal conductivity of cement paste for the construction of concrete buildings in sustainable cities
}

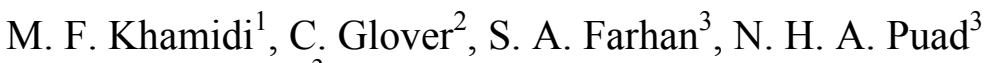 \\ \& M. F. Nuruddin ${ }^{3}$ \\ ${ }^{I}$ School of the Built Environment, Heriot-Watt University Malaysia, \\ Malaysia \\ ${ }^{2}$ Department of Civil and Environmental Engineering, P C Rossin \\ College of Engineering and Applied Science, Lehigh University, USA \\ ${ }^{3}$ Department of Civil Engineering, Faculty of Engineering, \\ Universiti Teknologi PETRONAS, Malaysia
}

\begin{abstract}
The objective of this paper is to evaluate the effect of silica aerogel on the thermal conductivity of cement paste for the construction of concrete buildings in sustainable cities. Samples consisting of Ordinary Portland Cement (OPC), free water and different volumes of silica aerogel were prepared and cured for three (3), seven (7) and 28 days. Compressive strength tests were performed on samples at three (3), seven (7) and 28 days of curing. Porosity and thermal conductivity tests were conducted on samples at 28 days of curing. The lowest thermal conductivity measured was $0.076 \mathrm{~W} / \mathrm{mK}$, which was achieved by sample mix with $20 \mathrm{ml}$ of silica aerogel (M20), which represents a $93.58 \%$ reduction in thermal conductivity relative to the control mix. The highest permeable porosity measured for cement paste incorporated with silica aerogel was $25.6 \%$, which was also obtained by sample M20. However, the highest compressive strength measured was $54.33 \mathrm{MPa}$, which was obtained by sample mix with $10 \mathrm{ml}$ of silica aerogel (M10) at 28 days of curing. The addition of silica aerogel as filler in cement paste can reduce the thermal conductivity of cement paste at the expense of reduced compressive strength and increased permeable porosity. Keywords: silica aerogel, cement paste, filler, thermal conductivity, thermal insulation, concrete, compressive strength, permeable porosity.
\end{abstract}




\section{Introduction}

The desire to achieve indoor thermal comfort among building occupants in a hot climate encourages the use of room air-conditioners $(\mathrm{AC})$ that can reduce indoor temperature and humidity. However, room AC consumes a lot of energy and contributes negatively to global warming [1]. A sustainable city should consist of buildings that do not consume a lot of energy and contributes positively towards the mitigation of global warming. Dependence on $\mathrm{AC}$ can be reduced by installing building insulation that can retard heat flow into the building [2]. In contrast, the current knowledge on building insulation among building owners and developers in Malaysia is low [3], which is due to many factors that includes lack of promotion on the benefits of insulation by manufacturers and also lack of research on building insulation, especially for buildings under hot-humid climate like Malaysia [4]. Furthermore, other than having low thermal conductivity, building insulation materials also need to possess high compressive strength and fulfill other requirements in order to become a viable building material, which provides challenges on the implementation of building insulation [5].

Silica aerogel is a nano material with remarkable properties such as high specific surface area, high porosity, low density, low dielectric constant and excellent heat insulation properties [6] and has the potential to become an effective building insulation material. However, the implementation of silica aerogel as building insulation is restricted due to the high cost to manufacture them. To add to that, it is also very fragile due to its low tensile strength, despite having a relatively high compressive strength [5].

A novel method to produce silica aerogels through the extraction of silica from rice husks instead of sand was discovered in 2005, which can reduce the manufacturing cost of silica aerogel by $80 \%$ [7]. Other than reducing cost, the method also contributes positively towards global warming because rice husks are waste materials. Figure 1 shows silica aerogel in block form.

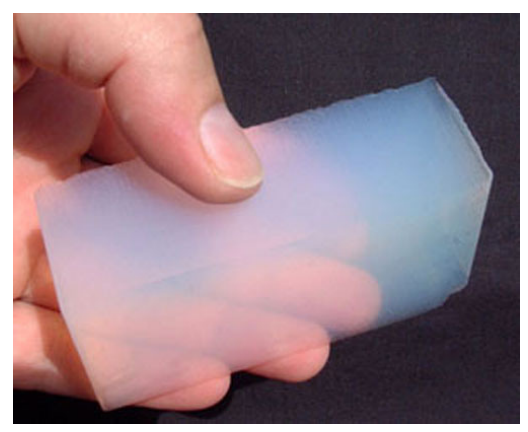

Figure 1: Silica aerogel in block form.

Most buildings in the present time are made of concrete and cement paste is one of the main constituents of concrete. There are a lot of researches that explore the addition of new materials such as petroleum coke [8], limestone [9], 
rubber [10], silica fume [11, 12] and microwave incinerated rice husk ash (MIRHA) [11] in cement paste to lower its thermal conductivity. Due to the brittleness of silica aerogel, adding silica aerogel in powder form in cement paste is a potential method of applying silica aerogel as building insulation. The objective of this paper is to evaluate the effect of silica aerogel on thermal conductivity of cement paste for construction of concrete buildings in sustainable cities.

\section{Methodology}

Firstly, samples consisting of Ordinary Portland Cement (OPC), free water and different volumes of silica aerogel were prepared and cured for three (3), seven (7) and 28 days. Then, compressive strength tests were performed on samples at three (3), seven (7) and 28 days of curing. Next, porosity and thermal conductivity tests were conducted on samples at 28 days of curing. Lastly, results are interpreted.

\subsection{Preparation of constituent materials}

OPC and free water were selected and prepared based on standards outlined in BS EN 197-1:2011 [13] and BS 3148:1980 [14]. Silica aerogel in powder form (Figure 2) with density of $0.168 \mathrm{~g} / \mathrm{cm}^{3}$ were obtained from a local manufacturer and adopted as filler material. The silica aerogel is prepared according to [15].

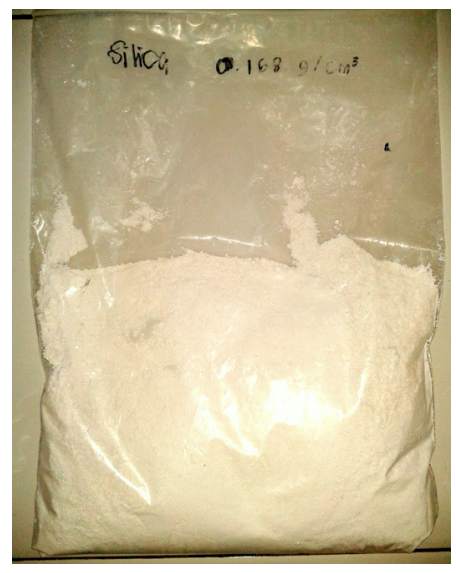

Figure 2: Silica aerogel in powder form.

\subsection{Preparation of cement paste samples}

Cement paste with 0.5 water-cement ratio was mixed according to procedures outlined in ASTM C305-99 [16]. One (1) mix with no filler and four (4) mixes with $5 \mathrm{ml}, 10 \mathrm{ml}, 15 \mathrm{ml}$ and $20 \mathrm{ml}$ of silica aerogel were casted in steel moulds with dimensions of $50 \mathrm{~mm}$ x $50 \mathrm{~mm}$ x $50 \mathrm{~mm}$ for 24 hours. Then, samples were 
cured with water in the curing tank at $25 \pm 2{ }^{\circ} \mathrm{C}$ water temperatures in accordance with BS EN 12390-2:2000 [17].

\subsection{Compressive strength test}

Compressive strength tests were conducted on all mixes at three (3), seven (7) and 28 days of curing in accordance with BS EN 12390-3:2002 [18] using the Digital Compressive Testing Machine as shown in Figure 3. Samples were subjected to compressive loading at a rate of $0.9 \mathrm{kNs}^{-1}$. The compressive strength is the maximum load that the sample can withstand before failure per unit of cross-sectional area of the sample. An average reading of three (3) samples was taken for each type of mix.

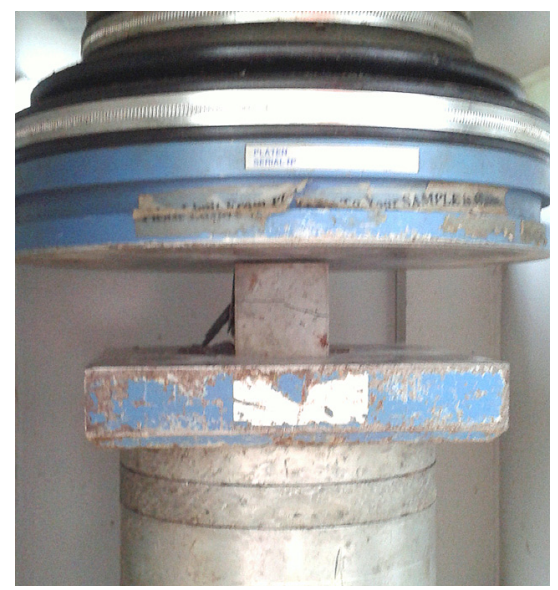

Figure 3: A sample subjected to compressive loading by the digital compressive testing machine

\subsection{Permeable porosity test}

Permeable porosity tests were performed on each mix. Samples were dried in the oven at $110 \pm 10^{\circ} \mathrm{C}$ after 28 days of curing and mass of samples were taken at 24-hour intervals until the reduction in mass per interval does not exceed $1 \%$. Then, the saturated surface-dry mass of samples in air $\left(\mathrm{W}_{\mathrm{s}}\right)$, oven-dry mass of samples in air $\left(\mathrm{W}_{\mathrm{d}}\right)$ and buoyant mass of saturated samples in water $\left(\mathrm{W}_{\mathrm{b}}\right)$ are used to calculate permeable porosity as shown in Equation (1).

Permeable porosity $=\frac{\mathrm{W}_{\mathrm{s}}-\mathrm{W}_{\mathrm{d}}}{\mathrm{W}_{\mathrm{s}}-\mathrm{W}_{\mathrm{b}}} \times 100 \%$

An average reading of three (3) samples was taken for each type of sample mix. 


\subsection{Thermal conductivity test}

Thermal conductivity tests were performed on each mix on samples at 28 days of curing using the thermal conductivity analyzer (as shown in Figure 4). Average readings of five (5) readings were taken at one-minute intervals for each type of mix.

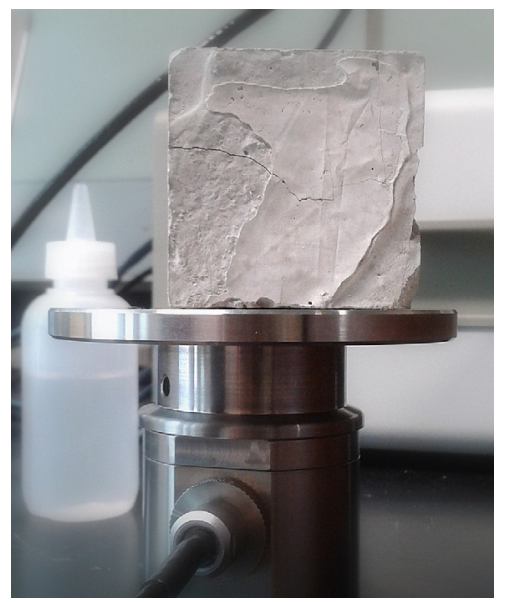

Figure 4: Thermal conductivity of a sample measured by the sensor of the thermal conductivity analyzer.

\section{Results and discussion}

Results are presented and interpreted accordingly. Table 1 presents the abbreviations used for each mix for presentation and interpretation of results.

Table 1: Abbreviations for each mix.

\begin{tabular}{|c|c|}
\hline Abbreviation & Mix \\
\hline Control & Cement paste with no filler \\
\hline M5 & Cement paste with $5 \mathrm{ml}$ silica aerogel as filler \\
\hline M10 & Cement paste with $10 \mathrm{ml}$ silica aerogel as filler \\
\hline M15 & Cement paste with $15 \mathrm{ml}$ silica aerogel as filler \\
\hline M20 & Cement paste with $20 \mathrm{ml}$ silica aerogel as filler \\
\hline
\end{tabular}

\subsection{Effect of silica aerogel on compressive strength}

Figures 5 to 8 present the compressive strength of each mix at three (3), seven (7) and 28 days of curing. It was found that the addition of silica aerogel as filler in cement paste initially increases its compressive strength until it reaches a maximum compressive strength, after which its compressive strength decreases. 


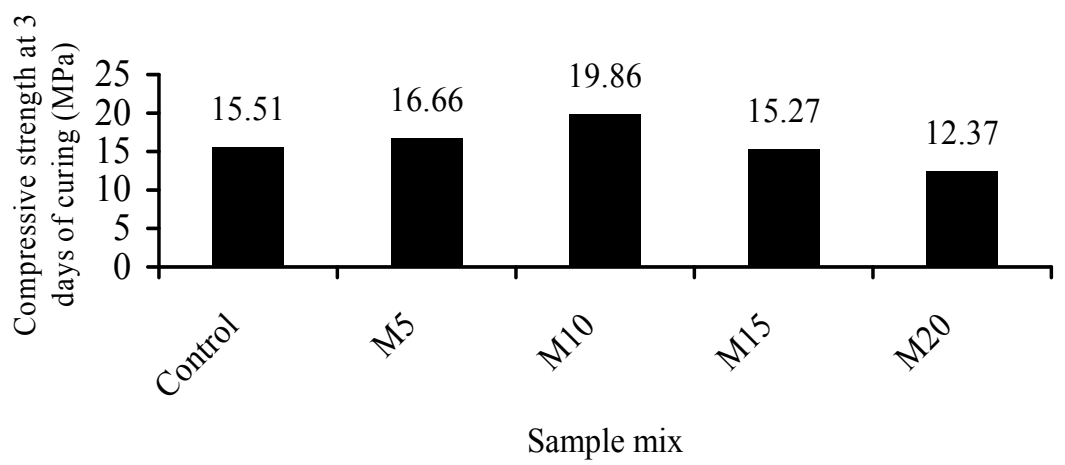

Figure 5: Compressive strength at three (3) days of curing of all mixes.

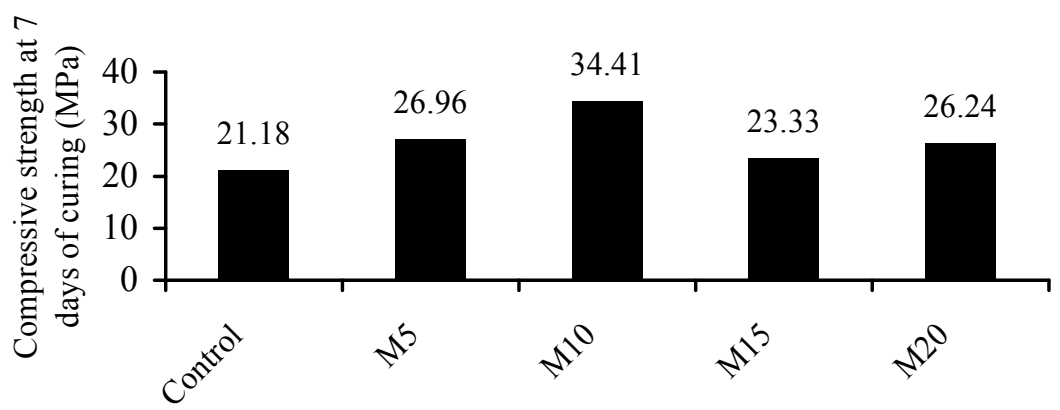

Sample mix

Figure 6: Compressive strength at seven (7) days of curing of all mixes.

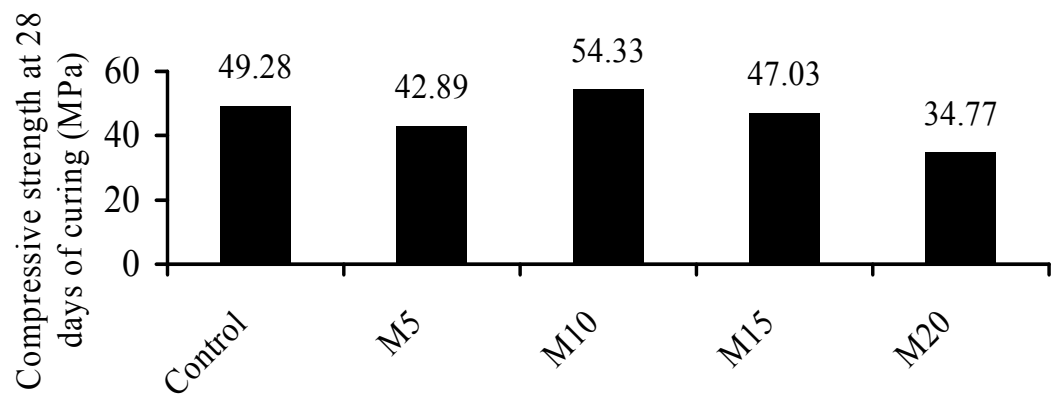

Sample mix

Figure 7: Compressive strength at 28 days of curing of mixes. 


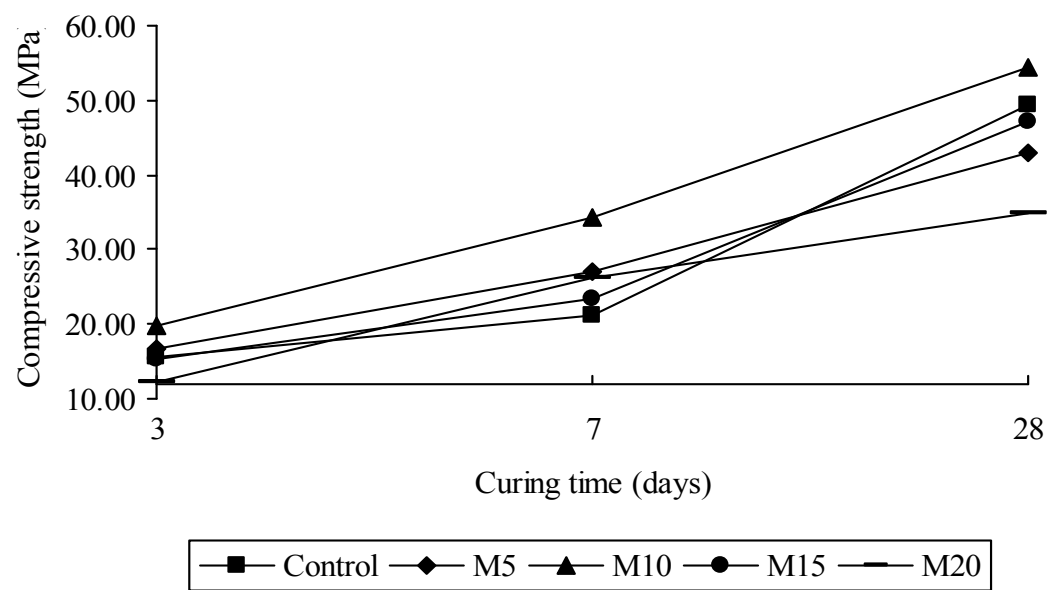

Figure 8: Compressive strength at all curing days of all mixes.

The silica aerogel initially strengthens the cement paste by filling in the pores. After all the pores are filled in, further addition of silica aerogel will lead to a decrease in the overall compressive strength of the sample because of the compressive strength of the silica aerogel itself, which is lower than the cement paste. The highest compressive strength measured was $54.33 \mathrm{MPa}$, which was obtained by sample M10 at 28 days of curing.

\subsection{Effect of silica aerogel on permeable porosity}

Figure 9 shows that addition of silica aerogel as filler in cement paste increases its permeable porosity. The increase in permeable porosity is due to the lower permeable porosity of silica aerogel compared to cement paste. The highest permeable porosity measured was $25.6 \%$, which was obtained by sample M20.

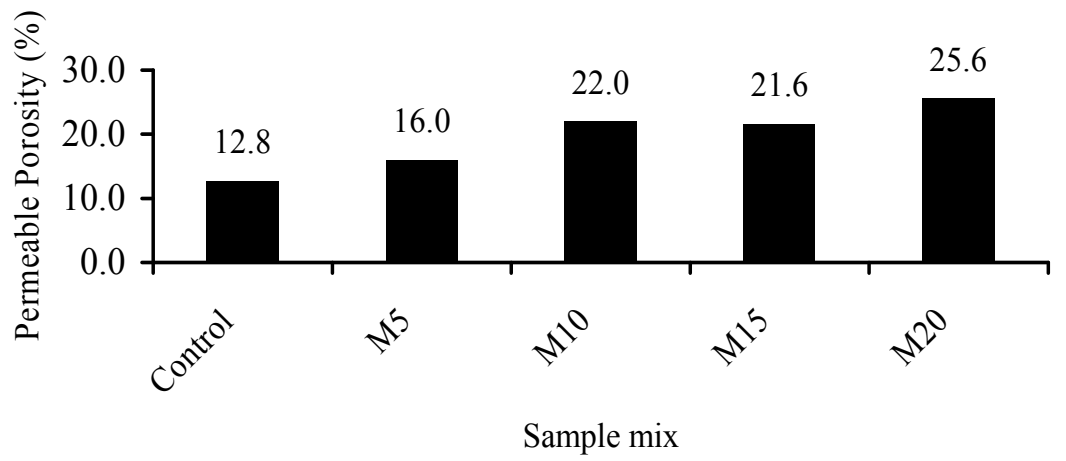

Figure 9: Permeable porosity of all mixes. 


\subsection{Effect of silica aerogel on thermal conductivity}

Figure 10 shows that the silica aerogel filler decreases thermal conductivity of cement paste and thus improves thermal insulation.

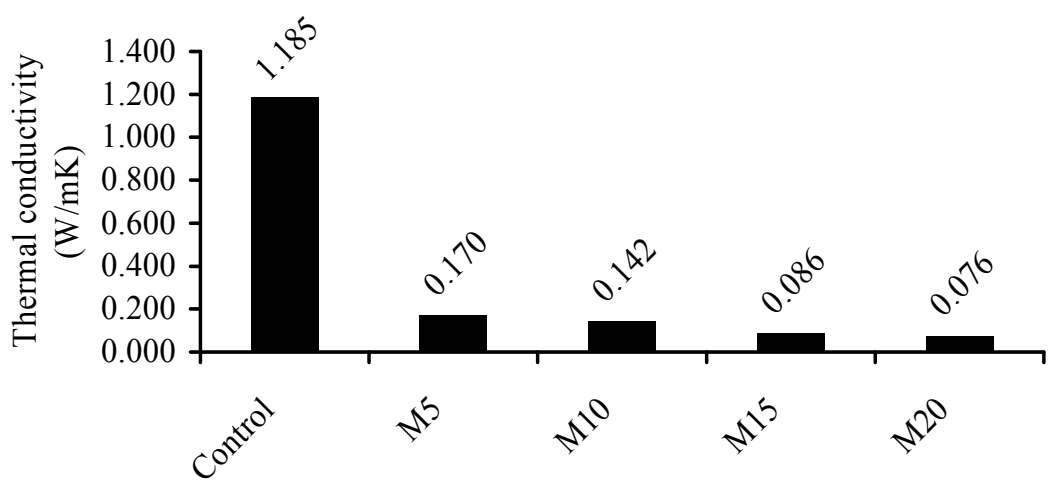

Sample mix

Figure 10: Thermal conductivity values for all mixes.

The lowest thermal conductivity measured for cement paste incorporated with silica aerogel was $0.076 \mathrm{~W} / \mathrm{mK}$, which was obtained by sample M20. This represented a $93.59 \%$ reduction compared to the control mix. In another study, petroleum coke with high sulphur content with different particle sizes were added to OPC pastes and mortars. The lowest thermal conductivity measured is $0.12 \mathrm{~W} / \mathrm{mK}$, which was obtained by paste samples containing $75 \%$ petroleum coke by weight. and represented a $76 \%$ reduction in thermal conductivity compared to control samples [8]. The addition of rubber in cement was also proven to be able to reduce the thermal conductivity of cement [10]. Similarly to silica aerogel, a study found that increasing the volume of silica fume and MIRHA in cement paste also leads to lower thermal conductivity but at the same time leads to lower compressive strength and higher permeable porosity. The lowest thermal conductivity value obtained in this study was $0.4273 \mathrm{~W} / \mathrm{mK}$, which was achieved by samples with MIRHA incorporated at $25 \%$ of cement paste volume [11].

\section{Conclusion}

Despite the positive effect on thermal conductivity, incorporation of silica aerogel in cement paste leads to increased permeable porosity and lower compressive strength. Findings suggest that higher volumes of silica aerogel in cement paste lead to lower thermal conductivity but negatively affect compressive strength and permeable porosity. The lowest thermal conductivity measured was $0.076 \mathrm{~W} / \mathrm{mK}$ which was achieved by M20 and presents a $93.58 \%$ 
reduction in thermal conductivity relative to the control sample. The highest permeable porosity measured for cement paste incorporated with silica aerogel was $25.6 \%$, which was also obtained by sample M20. However, the highest compressive strength measured was $54.33 \mathrm{MPa}$, which was obtained by sample M10 at 28 days of curing.

In conclusion, the addition of silica aerogel as filler in cement paste can reduce the thermal conductivity of cement paste at the expense of reduced compressive strength and increased permeable porosity. It is recommended that further research is conducted to investigate the effect of adding silica aerogel as filler in cement mortar or concrete samples.

\section{References}

[1] Leo Samuel, D. G., Shiva Nagendra, S. M. \& Maiya, M. P., Passive alternatives to mechanical air conditioning of building: A review, Building and Environment, 66, pp. 54-64, 2013.

[2] Farhan, S. A., Khamidi, M. F., Ziela, D. F., Yacouby, A. M. A., Idrus, A., Nuruddin, M. F. \& Razali, A. E., "Performance of reflective insulation in gable roofs: Small-scale experimental investigation," presented at the International Conference on Civil, Offshore \& Environmental Engineering, Kuala Lumpur, Malaysia, 2012.

[3] Yacouby, A. M. A., Khamidi, M. F., Teo, Y. W., Nuruddin, M. F., Farhan, S. A., Sulaiman, S. A. \& Razali, A. E., "Housing developers and home owners awareness on implementation of building insulation in Malaysia," WIT Transactions on Ecology and the Environment, 148, pp. 219-230, 2011.

[4] Farhan, S. A., Khamidi, M. F., Yacouby, A. M. A., Idrus, A. \& Nuruddin, M. F., "Critical Review of Published Research on Building Insulation: Focus on Building Components and Climate," presented at the IEEE Business, Engineering \& Industrial Applications Colloqium, Kuala Lumpur, Malaysia, 2012.

[5] Jelle, B. P., Traditional, state-of-the-art and future thermal building insulation materials and solutions - properties, requirements and possibilities, Energy and Buildings, 43, pp. 2549-2563, 2011.

[6] Dorcheh, A. S. \& Abbasi M. H., Silica aerogel; synthesis, properties and characterization, Journal of Materials Processing Technology, 199, pp. 10-26, 2008.

[7] Hamdan, H., "Nanomaterials as catalysts in the production of fine chemicals," Akta Kimindo, 1, pp. 1-10, 2005.

[8] Olmedaa, J., Sánchez de Rojas, M. I., Frías, M., Donatello, S. \& Cheeseman C. R., Effect of petroleum (pet) coke addition on the density and thermal conductivity of cement pastes and mortars, Fuel, 107, pp. 138-146, 2013. 
[9] Corinaldesi, V., Mazzoli A. \& Moriconi, G., Mechanical behaviour and thermal conductivity of mortars containing waste rubber particles, Materials \& Design, 32 (3), pp. 1646-1650, 2011.

[10] Benazzouk, A., Douzane, O., Mezreb, K., Laidoudi, B. \& Quéneudec, M., Thermal conductivity of cement composites containing rubber waste particles: Experimental study and modeling, Construction and Building Materials, 22, pp. 573-579, 2008.

[11] Farhan, S. A., Khamidi, M. F., Murni, M. H., Nuruddin, M. F., Idrus, A. \& Al Yacouby, A. M., "Effect of silica fume and MIRHA on thermal conductivity of cement paste," High Performance Structures and Materials VI. WIT Transactions on the Built Environment, 124, pp. 331339, 2012.

[12] Xu, Y. \& Chung, D. D. L., Cement of high specific heat and high thermal conductivity, obtained by using silane and silica fume as admixtures, Cement and Concrete Research, 30, pp. 1175-1178, 2000.

[13] BS EN 197-1, Cement. Composition, specifications and conformity criteria for common cements, British European Standard, 2011.

[14] BS 3148-1980, Method for test for water for making concrete, British Standard, 1980.

[15] Hamdan, H., Silica aerogels, United States Patent 10/578,774, 2007.

[16] ASTM C305-99, Standard Practice for Mechanical Mixing of Hydraulic Cement Pastes and Mortars of Plastic Consistency, ASTM International Standard, 1999.

[17] BS EN 12390-2:2000, Testing hardened concrete. Making and curing specimens for strength tests, British European Standard, 2000.

[18] BS EN 12390-3:2002, Compressive Strength of Test Cubes, British European Standard, 2002. 